\title{
Expression Level of Wnt5a Was Related to the Therapeutic Effects of First-Generation EGFR-TKls
}

This article was published in the following Dove Press journal: OncoTargets and Therapy

\author{
Hai Zhang ${ }^{1, *}$ \\ Xiaohua Yang ${ }^{2, *}$ \\ Fang $\mathrm{Hu}^{\mathrm{l}, *}$ \\ Changhui $\mathrm{Li}^{\prime}$ \\ Jianlin $X u^{\prime}$ \\ Wei Nie \\ Yinchen Shen' \\ Yuqing Lou (D)' \\ Baohui Han' \\ Hua Zhong' \\ Xueyan Zhang $\mathbb{D}^{\prime}$ \\ 'Department of Pulmonary, Shanghai \\ Chest Hospital, Shanghai Jiao Tong \\ University, Shanghai 200030, People's \\ Republic of China; ${ }^{2}$ Central Laboratory, \\ Shanghai Chest Hospital, Shanghai Jiao \\ Tong University, Shanghai 200030, \\ People's Republic of China \\ *These authors contributed equally to \\ this work
}

\begin{abstract}
Background and Objective: The first-generation epidermal growth factor receptortyrosine kinase inhibitors (EGFR-TKIs) have shown significant therapeutic effects on patients harboring sensitive EGFR mutations, while the mechanisms related to drug resistance have still remained elusive. This study aimed to indicate the relationship between the expression level of Wnt5a with therapeutic effects of first-generation EGFR-TKIs on lung adenocarcinoma patients harboring sensitive EGFR mutations.
\end{abstract}

Methods: The medical records of 75 lung adenocarcinoma patients harboring sensitive EGFR mutations, who were admitted to our hospital and received first-generation EGFRTKIs from June 1, 2010 to December 31, 2016, were analyzed. According to the efficacy of first-generation EGFR-TKIs, patients were divided into ineffective groups (progression-free survival (PFS) $<5$ months) and effective groups (PFS $>26$ months). Immunofluorescence staining, immunohistochemical staining and reverse transcription polymerase chain reaction (RT-PCR) methods were utilized to detect the expression level of Wnt5a in the two groups. Results: Among 75 patients, 36 patients were sensitive to first-generation EGFR-TKIs (effective group) and 39 patients were resistant to first-generation EGFR-TKIs (ineffective group). The location of Wnt5a was detected by immunofluorescence staining. Immunohistochemical staining demonstrated that the expression level of Wnt5a in the ineffective group was significantly higher than that in the effective group $(\mathrm{P}=0.0216)$. Besides, results of RT-PCR showed that the relative expression level of Wnt5a was remarkably higher in the ineffective group than that in the effective group $(\mathrm{P}=0.0135)$.

Conclusion: The expression level of Wnt5a was found to be associated with therapeutic effects of first-generation EGFR-TKIs in lung adenocarcinoma patients harboring sensitive EGFR mutations.

Keywords: tyrosine-kinase inhibitors, Wnt5a, epidermal growth factor receptor mutation, therapeutic effect

\section{Introduction}

Lung cancer is one of the leading causes of cancer-related death worldwide. ${ }^{1}$ Patients with epidermal growth factor receptor (EGFR) mutation-positive non-small cell lung cancer (NSCLC) are highly sensitive to EGFR-tyrosine kinase inhibitors (TKIs) with response rates and progression-free survival (PFS) typically ranging from $56 \%$ to $83 \%$ and 8.4-18.9 months, respectively. ${ }^{2-4}$ However, despite a dramatic initial response, almost all patients treated with EGFR-TKIs eventually develop acquired resistance to these drugs with a median time to disease progression of $10-14$ months. ${ }^{5-7}$ Some studies have discussed the mechanism of drug resistance, but the underlying mechanism of drug resistance has not been fully elucidated. ${ }^{8}$
Correspondence: Xueyan Zhang; Hua Zhong

Department of Pulmonary, Shanghai Chest Hospital, Shanghai Jiao Tong University, Shanghai 200030, People's Republic of China Tel +86 I80I732I3।9; +86 I38I8200560

Fax +86-02I-62821990

Email zxychest@163.com;

eddiedong8@hotmail.com 
The Wnt genes encode a large family of secreted polypeptides that participate in various physiological and pathological processes, such as tumor formation, embryogenesis and differentiation. ${ }^{9,10}$ Wnt5a, a member of the Wnt family of proteins, has been shown to play distinct roles during embryogenesis, organ homeostasis, and in adult cellular processes. ${ }^{11}$ A previous study demonstrated that high Wnt5a expression is associated with poor prognosis in NSCLC patients. ${ }^{12}$ However, whether the expression of Wnt5a is related to the therapeutic efficacy of firstgeneration of EGFR-TKIs has still remained elusive.

Within $60 \%$ of acquired resistance to the first-generation EGFR-TKIs results from EGFR exon 20 T790M mutations. ${ }^{8}$ To date, some mechanisms related to drug resistance of EGFR-TKIs have been elucidated, while several mechanisms have remained unclear. It has been pointed out that cancer stem cells (CSCs) are the main source of resistance to drug treatment. ${ }^{13}$ Studies reported that Wnt pathway plays an important role in the maintenance of CSCs in lung cancer. $^{14,15}$ Therefore, we speculated that the expression level of Wnt5a is one of the potential mechanisms related to the resistance of first-generation EGFR-TKIs. Therefore, the present study aimed to assess the relationship between the expression level of Wnt5a with therapeutic effects of firstgeneration EGFR-TKIs on lung adenocarcinoma patients harboring sensitive EGFR mutations.

\section{Patients and Methods}

\section{Patients}

The medical records of 75 lung adenocarcinoma patients harboring sensitive EGFR mutations, who were admitted to Shanghai Chest Hospital (Shanghai, China) and received firstgeneration EGFR-TKIs from June 1, 2010 to December 31, 2016, were analyzed. The inclusion criteria were as follows: 1 ) lung adenocarcinoma patients harboring sensitive EGFR mutation; 2) consideration of first-generation EGFR-TKIs (eg, erlotinib, icotinib, or gefitinib) as first-line treatment; and 3) the patients who received first-generation EGFR-TKIs and had short progression-free survival (PFS) $(<5$ months) or long PFS ( $>26$ months). It should be noted that the PFS of first-generation EGFR-TKIs is typically 10-13 months. ${ }^{3}$ Therefore, patients were divided into ineffective group (PFS $<5$ months) and effective group (PFS $>26$ months).

Exclusion criteria were as follows: patients with failure to follow-up, resistance mutations or unavailable EGFR mutation, incomplete medical records, or patients with history of other malignant tumors. Those patients who received radiotherapy or chemotherapy as first-line treatment were excluded as well. Eventually, 75 patients who met the criteria were included.

Clinical data included age, gender, smoking history, EGFR mutation, tumor-node-metastasis (TNM) stage, tumor differentiation, and carcinoembryonic antigen (CEA) level. The pathological tissue samples were obtained from Shanghai Chest Hospital (Shanghai, China). In addition, the ADx Amplification Refractory Mutation System (ADx-ARMS) was used to determine EGFR mutation status. This study was approved by the Ethics Committee of Shanghai Chest Hospital (KS1721), and it was carried out in accordance with the Declaration of Helsinki. All patients signed the written informed consent form prior to commencing the study.

\section{Immunohistochemical Staining}

The paraffin-embedded tissues were cut into $4 \mu \mathrm{m}$ sections with a microtome, and then baked at $65^{\circ} \mathrm{C}$ for more than 2 hours. The sections were de-paraffinized with xylene and then washed with gradient ethanol and distilled water (DW). The sections were heated in the antigen retrieval solution and then cooled to room temperature for antigen repair. Endogenous peroxidase was then removed with 3\% hydrogen peroxide, and goat serum was used to further eliminate specific staining. Then, Wnt5a antibody and slides were maintained at $4^{\circ} \mathrm{C}$ overnight. Peroxidaselabeled antibodies were applied at room temperature for 60 minutes to visualize antigens. Sections were then washed with phosphate-buffered saline (PBS), stained with 3,3'-diaminobenzidine (DAB), and further stained with hematoxylin and eosin (H\&E). Finally, the stained slides were examined in a blinded manner.

The staining intensity in the nuclei was scored as: 1 (weak); 2 (medium); and 3 (strong). Histoscore is a measure to convert classic immunohistochemistry into a more quantitative range. Histoscore or $\mathrm{H}$-score is based on staining intensity and percentages of stained cells. $\mathrm{H}-\mathrm{Score}$ is based on four immunohistochemistry categories reported: negative (0), weak $(1+)$, moderate $(2+)$, and strongly $(3+)$ stained membranes. In each case, a H-score with a potential range of 0-300 was calculated as follows: $\mathrm{H}$ score $=(1 \times \%$ weakly stained cells $)+(2 \times$ $\%$ moderately stained cells $)+(3 \times \%$ strongly stained cells)).

Human anti-Wnt5a (NBP2-24752SS; Novus Biologicals, Littleton, CO, USA) was used for immunohistochemical staining diluted in $5 \%$ PBS. 


\section{Immunofluorescence Staining}

After dewaxing and antigen retrieval, immunofluorescence staining was carried out. The sections were then washed with PBS (pH 7.3). Anti-Wnt5a polyclonal rabbit antibody (dilution, 1:100; Novus Biologicals, Littleton, CO, USA) was added to each section. The sections were then maintained at $4^{\circ} \mathrm{C}$ overnight. They were then thrice washed with PBS and stained with donkey anti-rabbit IgG secondary antibody (dilution 1:100; Jackson ImmunoResearch Laboratories, Inc., West Grove, PA, USA). As a control group, the primary antibody was replaced with PBS.

\section{Reverse Transcription Polymerase Chain Reaction (RT-PCR)}

Total RNA was extracted from tumor tissue by FFPE RNA kit (R6954-01; Omega Bio-tek, Inc., Norcross, GA, USA). And SuperMix was synthesized using Hifair II first-strand cDNA for RT-PCR (11123ES60; Yeasen, Shanghai, China). RT-PCR was performed on an Applied Biosystems ViiA 7 RT-PCR System (Applied Biosystems, Foster City, CA, USA) using UNICON $^{\circledR}$ qPCR SYBR Green Master Mix (11199ES08; Yeasen, Shanghai). Glyceraldehyde-3-phosphate dehydrogenase (GAPDH) was used as the housekeeping gene. The relative gene expression calculated using the $2^{\wedge}-\Delta \Delta \mathrm{Ct}$ method. The expression level of Wnt5a in each sample was calculated. The primer sequences of the gene were as follows:

Wnt5a-forward: 5'-TCGACTATGGCTACCGCTTTG-3'

Wnt5a-reverse: 5'-CACTCTCGTAGGAGCCCTTG-3'

GAPDH-forward: 5'-GGAGCG AGATCCCTCCAAAA $\mathrm{T}-3^{\prime}$

GAPDH-reverse: 5'-GGCTGTTGT CATACTTCTCAT GG-3'

\section{Statistical Analysis}

In this study, Student's $t$-test was used to detect differences in immunohistochemical staining and RT-PCR results between the two groups. The Chi-square test was utilized to detect differences in clinicopathological variables. Besides, $\mathrm{P}<0.05$ was considered statistically significant. All the analyses were undertaken by using SPSS 23.0 software (IBM, Armonk, NY, USA) and GraphPad 6.01 (GraphPad software Inc., San Diego, CA, USA) software.

\section{Results}

\section{Patients' Clinicopathological Features}

As a result, 75 eligible patients were included in the current study. The flowchart of patients' selection is shown in Figure 1. Among 75 patients, 36 were sensitive to first-

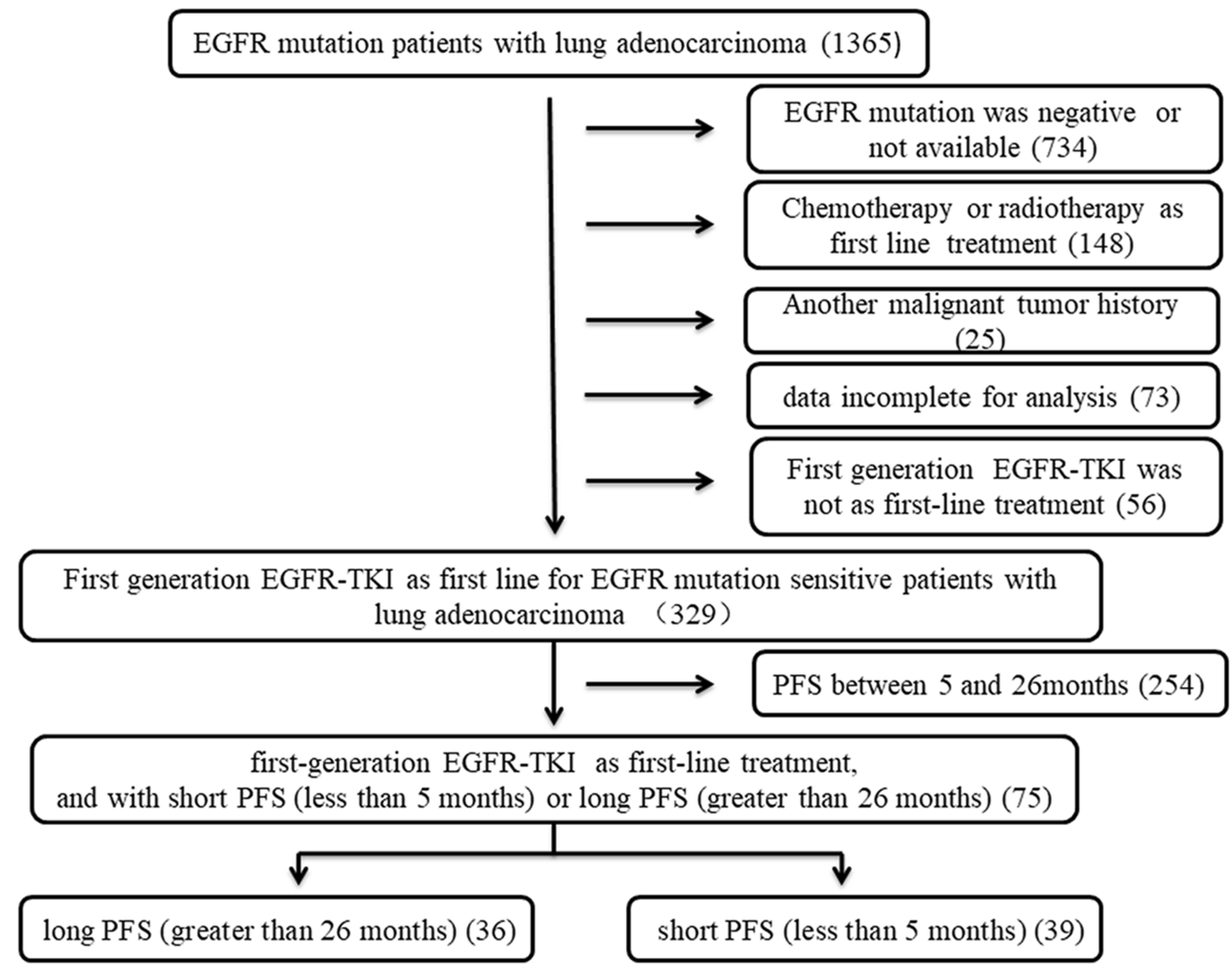

Figure I Patients' selection flowchart. EGFR, epidermal growth factor receptor; TKIs, tyrosine kinase inhibitors; PFS, progression-free survival. 
generation EGFR-TKIs (effective group) and 39 were insensitive to first-generation EGFR-TKIs (ineffective group). Besides, the variation of PFS between low- and high-level Wnt5a was illustrated in supplement Figure 1. The patients' median age was 57 years old (range, 34-71 years old). The patients' clinical features are listed in Table 1. The results of Chi-squared test showed that men were more susceptible to be involved in the ineffective group ( $\mathrm{P}=0.034)$. Furthermore, according to integrity of the gland structure, cell heterogeneity, and mucosal secretion, lung adenocarcinoma was classified as well differentiated, moderately differentiated, and poorly differentiated (Figure 2A).

Table I Patient Characteristics

\begin{tabular}{|c|c|c|c|c|}
\hline \multirow[t]{2}{*}{ Characteristic } & \multirow[t]{2}{*}{$\begin{array}{l}\text { No. of } \\
\text { Cases }\end{array}$} & $\begin{array}{l}\text { Effective } \\
\text { Group }\end{array}$ & $\begin{array}{l}\text { Ineffective } \\
\text { Group }\end{array}$ & \multirow[t]{2}{*}{$P$ value } \\
\hline & & n (\%) & n (\%) & \\
\hline $\begin{array}{l}\text { Age (years) } \\
\begin{array}{l}\leq 60 \\
>60\end{array}\end{array}$ & $\begin{array}{l}49 \\
26\end{array}$ & $\begin{array}{l}25(69.4 \%) \\
\mathrm{II}(30.6 \%)\end{array}$ & $\begin{array}{l}24(61.5 \%) \\
15(38.5 \%)\end{array}$ & 0.472 \\
\hline $\begin{array}{l}\text { Gender } \\
\text { Male } \\
\text { Female }\end{array}$ & $\begin{array}{l}28 \\
47\end{array}$ & $\begin{array}{l}9(25.0 \%) \\
27(75.0 \%)\end{array}$ & $\begin{array}{l}19(48.7 \%) \\
20(51.3 \%)\end{array}$ & 0.034 \\
\hline $\begin{array}{l}\text { Smoking history } \\
\text { Yes } \\
\text { No }\end{array}$ & $\begin{array}{l}23 \\
52\end{array}$ & $\begin{array}{l}9(25.0 \%) \\
27(75.0 \%)\end{array}$ & $\begin{array}{l}14(35.9 \%) \\
25(64.1 \%)\end{array}$ & 0.307 \\
\hline $\begin{array}{l}\text { EGFR mutation } \\
\qquad \begin{array}{l}\text { 19 del } \\
\text { 2IL858 } \\
\text { Others }\end{array}\end{array}$ & $\begin{array}{l}42 \\
31 \\
2\end{array}$ & $\begin{array}{l}22(61.1 \%) \\
13(36.1 \%) \\
I(2.8 \%)\end{array}$ & $\begin{array}{l}20(5 \mid .3 \%) \\
I 8(46.2 \%) \\
I(2.5 \%)\end{array}$ & 0.676 \\
\hline $\begin{array}{l}\text { TNM stage } \\
\text { IIIA/IIIB } \\
\text { IV }\end{array}$ & $\begin{array}{l}26 \\
49\end{array}$ & $\begin{array}{l}13(36.1 \%) \\
23(63.9 \%)\end{array}$ & $\begin{array}{l}13(33.3 \%) \\
26(66.7 \%)\end{array}$ & 0.801 \\
\hline $\begin{array}{l}\text { Differentiation } \\
\text { Well } \\
\text { Moderate } \\
\text { Poor }\end{array}$ & $\begin{array}{l}15 \\
28 \\
32\end{array}$ & $\begin{array}{l}9(25.0 \%) \\
15(41.7 \%) \\
12(33.3 \%)\end{array}$ & $\begin{array}{l}6(15.4 \%) \\
13(33.3 \%) \\
20(51.3 \%)\end{array}$ & 0.269 \\
\hline $\begin{array}{l}\text { CEA } \\
\text { Normal } \\
\text { Abnormal }\end{array}$ & $\begin{array}{l}37 \\
38\end{array}$ & $\begin{array}{l}16(44.4 \%) \\
20(55.6 \%)\end{array}$ & $\begin{array}{l}2 \mid(53.8 \%) \\
\mid 8(46.2 \%)\end{array}$ & 0.416 \\
\hline $\begin{array}{l}\text { EGFR-TKIs type } \\
\text { Gefitinib } \\
\text { Icotinib } \\
\text { Erlotinib }\end{array}$ & $\begin{array}{l}29 \\
37 \\
9\end{array}$ & $\begin{array}{l}14(38.9 \%) \\
17(47.2 \%) \\
5(13.9 \%)\end{array}$ & $\begin{array}{l}\mid 4(35.9 \%) \\
22(56.4 \%) \\
3(7.7 \%)\end{array}$ & 0.600 \\
\hline
\end{tabular}

Abbreviations: EGFR, epidermal growth factor receptor; TKI, tyrosine kinase inhibitor; TNM, tumor node metastasis; CEA, carcinoembryonic antigen.

\section{Correlations Between Clinicopathological} Features and the Expression Level of Wnt5a Correlations between the expression levels of Wnt5a with clinicopathological features of patients with lung adenocarcinoma who received first-line EGFR-TKIs were evaluated. As shown in Table 2, the expression level of Wnt5a was significantly correlated with PFS $(R=-0.226$, $\mathrm{P}=0.012$ ).

The correlation between the clinicopathological characteristics of 75 patients with lung adenocarcinoma and the expression level of Wnt5a was analyzed by chi-square test (Table 3). As a result, only the efficacy of firstgeneration EGFR-TKIs was correlation with wnt5a expression level $(\mathrm{P}=0.047)$.

\section{Immunofluorescence Staining and Immunohistochemical}

The representative confocal imaging of Wnt5a with immunofluorescence staining is displayed in Figure 2B. Then, we examined the expression level of Wnt5a in tissue samples of patients with significant prognostic differences by immunohistochemical staining, and the expression level of Wnt5a belonged to at last 52 cases was noted. The staining intensity is illustrated in Figure 2C. With calculation of $\mathrm{H}$-score, the expression level of Wnt5a was found significantly higher in the ineffective group than that in the effective group $(\mathrm{P}=0.0216$, Figure 3A).

\section{RT-PCR for Detecting the Expression Level of Wnt5a}

The expression level of Wnt5a was detected by RT-PCT. The results showed that the expression level of Wnt5a in the ineffective group $(\mathrm{P}=0.0135)$ was significantly higher than that in the effective group (Figure 3B).

\section{Discussion}

In the present study, there were totally 75 patients who were divided into two groups based on significant differences in the efficacy of first-generation EGFR-TKIs. Besides, the expression levels of Wnt5a in tumor tissues of the two groups were detected and compared. The results showed that the expression level of Wnt5a was markedly increased in the ineffective group compared with that in the effective group, indicating that the efficacy of the firstgeneration EGFR-TKIs may be related to the expression level of Wnt5a. 
A

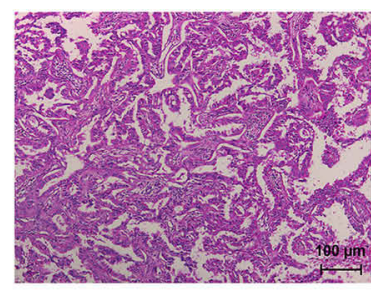

Well

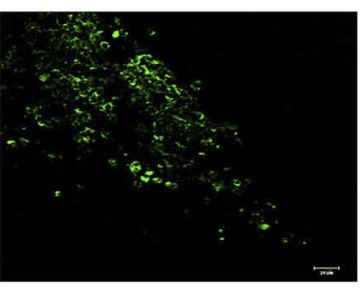

Wnt5a

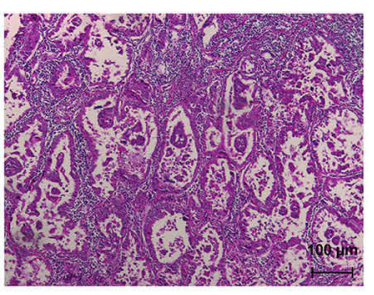

Moderate

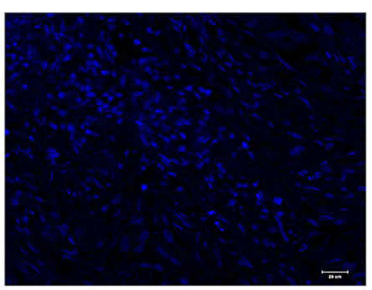

DAPI

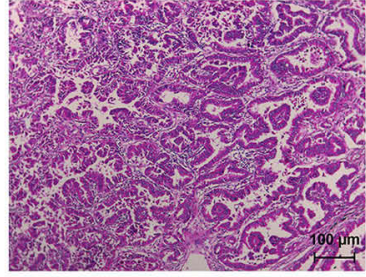

Poor

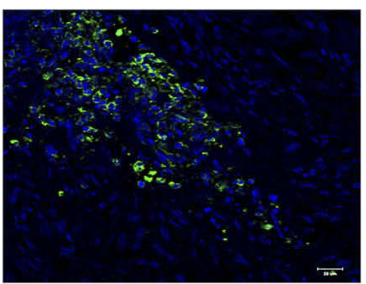

Merge

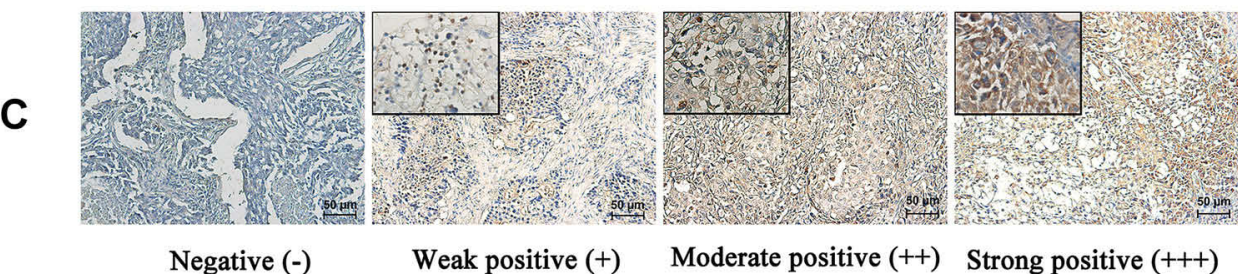

Figure 2 Representative images of samples with different degrees of differentiation, immunofluorescence staining and immunohistochemical staining. (A) According to the integrity of the gland structure, cell heterogeneity, and mucosal secretion, lung adenocarcinoma was classified as well differentiated, moderately differentiated, and poorly differentiated. Original magnification (OM) I00X. (B) Representative confocal images of Wnt5a with immunofluorescence staining in lung adenocarcinoma specimens. Nuclei were counterstained with 40, 6-diamidino-2-phenylindole (DAPl; blue). In the monochromatic-colored immunofluorescence images, all cancer cells expressing Wnt5a reflected green fluorescence. Original magnification (OM) 400X. (C) Representative images of Wnt5a with immunohistochemical staining in lung adenocarcinoma specimens (“-” means negative, “+” means weakly positive, “++” means moderately positive, and “+++” means strongly positive). Original magnification (OM) 200X.

EGFR plays a substantial role in the development and progression of malignant tumors by modulating downstream signaling pathways. ${ }^{16,17}$ However, almost all patients receiving the first-generation EGFR-TKIs may eventually experience tumor resistance and inevitably progress. ${ }^{18}$ Several possible resistance mechanisms have been reported, such as T790 mutation, HER2 amplification, MET amplification, PIK3CA mutation, BRAF mutation, NF1 deletions, etc. ${ }^{18-22}$ However, in addition to these proposed mechanisms, the mechanism underpinning the therapeutic resistance is still elusive. ${ }^{23}$ Therefore, it is essential to explore more potential drug resistance mechanisms, leading to further improve the prognosis of patients harboring sensitive EGFR mutations.

While Wnt signaling plays a critical role in numerous cellular and developmental processes in normal cells, aberrant Wnt signaling is highly associated with numerous cancers and may be responsible for drug resistance and recurrence of tumor. A study demonstrated that Wnt signaling pathway can inhibit proliferation of lung CSCs (LCSCs), and it can be taken as a promising therapeutic or interventional target into consideration in lung adenocarcinoma. ${ }^{24}$ Another study also confirmed that Wnt signaling pathway plays a substantial role in regulation of various cellular processes, including cell survival,

Table 2 Correlation of Wnt5a Expression with Clinicopathological Variables

\begin{tabular}{|l|l|l|l|l|l|l|l|l|}
\hline Characteristic & $\begin{array}{l}\text { PFS Status(<5 Months, } \\
\text { >26 Months) }\end{array}$ & Age & Gender & $\begin{array}{l}\text { Smoking } \\
\text { History }\end{array}$ & $\begin{array}{l}\text { EGFR } \\
\text { Mutation }\end{array}$ & $\begin{array}{l}\text { TNM } \\
\text { Stage }\end{array}$ & Differentiation & CEA \\
\hline$R$ & -0.226 & -0.012 & 0.030 & -0.053 & -0.017 & 0.046 & -0.010 & -0.009 \\
$P$ value & $0.012^{*}$ & 0.896 & 0.740 & 0.564 & 0.856 & 0.618 & 0.917 & 0.924 \\
\hline
\end{tabular}

Notes: ${ }^{*} p<0.05$ was considered significant. Correlation was determined by spearman test. $\mathrm{R}$ means correlation index.

Abbreviations: PFS, progression-free survival; EGFR, epidermal growth factor receptor; TNM, tumor node metastasis; CEA, carcinoembryonic antigen. 
Table 3 Patients Characteristics Between Wnt5a Expression* and Clinicopathological Variables

\begin{tabular}{|c|c|c|c|}
\hline Characteristic & $\begin{array}{l}\text { Positive, } \\
\text { n (\%) }\end{array}$ & $\begin{array}{l}\text { Negative, } \\
\text { n (\%) }\end{array}$ & $P$ value \\
\hline $\begin{array}{l}\text { Efficacy } \\
\text { Effective (PFS> 26m) } \\
\text { Ineffective (PFS }<5 \mathrm{~m})\end{array}$ & $\begin{array}{l}2 I(40.4) \\
3 I(59.6)\end{array}$ & $\begin{array}{l}15(65.2) \\
8(34.8)\end{array}$ & 0.047 \\
\hline $\begin{array}{l}\text { Age (years) } \\
\quad<60 \\
>60\end{array}$ & $\begin{array}{l}34(65.4) \\
18(34.6)\end{array}$ & $\begin{array}{l}15(65.2) \\
8(34.8)\end{array}$ & 0.989 \\
\hline $\begin{array}{l}\text { Gender } \\
\text { Male } \\
\text { Female }\end{array}$ & $\begin{array}{l}20(38.5) \\
32(61.5)\end{array}$ & $\begin{array}{l}8(34.8) \\
15(65.2)\end{array}$ & $0.76 \mathrm{I}$ \\
\hline $\begin{array}{l}\text { Smoking history } \\
\text { Yes } \\
\text { No }\end{array}$ & $\begin{array}{l}17(32.7) \\
35(67.3)\end{array}$ & $\begin{array}{l}6(26.1) \\
17(73.9)\end{array}$ & 0.567 \\
\hline $\begin{array}{l}\text { EGFR mutation } \\
\qquad \begin{array}{l}19 \text { del } \\
2 \text { IL858 } \\
\text { Others }\end{array}\end{array}$ & $\begin{array}{l}29(55.8) \\
21(40.4) \\
2(3.8)\end{array}$ & $\begin{array}{l}13(56.5) \\
10(43.5) \\
0(0)\end{array}$ & 0.630 \\
\hline $\begin{array}{l}\text { TNM stage } \\
\text { IIIA/IIIB } \\
\text { IV }\end{array}$ & $\begin{array}{l}16(30.8) \\
36(69.2)\end{array}$ & $\begin{array}{l}10(43.5) \\
13(56.5)\end{array}$ & 0.286 \\
\hline $\begin{array}{l}\text { Differentiation } \\
\text { Well } \\
\text { Moderate } \\
\text { Poor }\end{array}$ & $\begin{array}{l}I I(2 \mid .2) \\
19(36.5) \\
22(42.3)\end{array}$ & $\begin{array}{l}4(17.4) \\
9(39.1) \\
10(43.5)\end{array}$ & 0.929 \\
\hline $\begin{array}{l}\text { CEA } \\
\text { Normal } \\
\text { Abnormal }\end{array}$ & $\begin{array}{l}25(48.1) \\
27(51.9)\end{array}$ & $\begin{array}{l}12(52.2) \\
11(47.8)\end{array}$ & 0.743 \\
\hline
\end{tabular}

Notes: ${ }^{*}$ The expression of wnt 5 a was evaluated by $\mathrm{H}$ score of immunohistochemistry (Positive: H Score >0; Negative: H Score=0).

Abbreviations: PFS, progression-free survival; EGFR, epidermal growth factor receptor; TNM, tumor node metastasis; CEA, carcinoembryonic antigen.

proliferation, cell fate specification, migration and selfrenewal of CSCs. ${ }^{25}$ Besides, among the Wnt protein family, Wnt5a is an important potential target for cancer treatment. ${ }^{26} \mathrm{Wnt5a}$ is known as a typical non-canonical ligand that is up-regulated in various types of cancers, including gastric cancer, pancreatic cancer, and prostate cancer. ${ }^{27-29}$ In addition, Wnt5a can promote the cisplatin resistance of lung cancer cells through the Wnt signaling pathway. ${ }^{30}$ A number of scholars pointed out that the gemcitabine resistance of bladder cancer cells is improved after targeted inhibition of Wnt5a. ${ }^{11}$ Our previous study had also demonstrated that the Wnt signaling pathway is involved in regulation of LCSCs, and Wnt5a is significantly increased by functional genome analysis of Wnt signaling in LCSCs. ${ }^{31}$ Therefore, based on the abovementioned findings, we speculate that the resistance of the first-generation EGFR-TKIs may be related to the expression levels of Wnt5a and CSCs.

To our knowledge, CSCs are an obstacle in cancer therapy and are a major cause of drug resistance, cancer recurrence, and metastasis. CSCs are responsible for drug resistance and cancer relapse due in part to their ability to self-renew themselves and differentiate into heterogeneous lineages of cancer cells. ${ }^{13}$ A number of studies reported that cytotoxic chemotherapy and targeted therapy kill the majority of cancer cells, except for CSCs. ${ }^{32,33}$ Whether high expression level of Wnt5a promotes the resistance of first-generation EGFR-TKIs through CSCs need to be clarified. To improve the rationality of our hypothesis, we, in the present study, constructed a mouse xenograft model to analyze the relationship between the expression level of Wnt5a and CSCs. We found that CSCs successfully formed tumors in mice (Figure S2 A). With the analysis of mouse tumor cells, Wnt5a was highly expressed (Figure S2 B1). Furthermore, after using antiCSCs therapies, the expression level of wnt5a was reduced (Figure S2 B2). Therefore, it can be concluded that the high expression level of Wnt5a may be related to the activity of LCSC.

The above research indicated that Wnt5a is highly expressed in tumor tissues, and the therapeutic effects of the first generation of EGFR-TKIs are associated with the expression level of Wnt5a. Although the underlying mechanism remains unclear, we speculated that the expression level of Wnt5a may be related to the existence of LCSCs in combination with our previous research, which led to the inefficiency of the first generation of EGFR-TKIs.

The present study has a number of limitations that should be pointed out. Firstly, the sample size was small. Secondly, we did not comprehensively study the specific mechanisms for drug resistance. Thus, we will further expand the sample size and clarify those mechanisms in the future research.

In conclusion, the expression level of Wnt5a is related to the therapeutic effects of first-generation EGFR-TKIs in lung adenocarcinoma patients harboring sensitive EGFR mutation. Therefore, Wnt5a can be regarded as a potential predictor and therapeutic target for the efficacy of the firstgeneration EGFR-TKIs. 
A

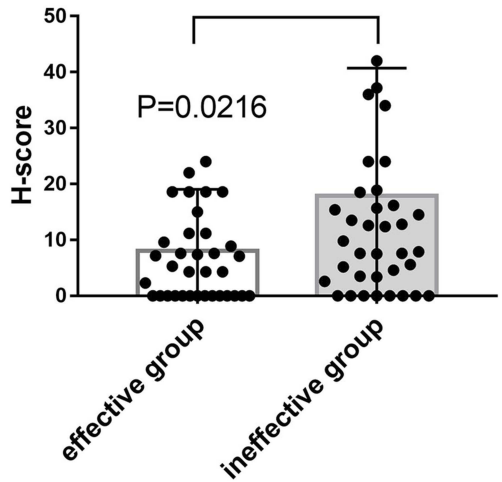

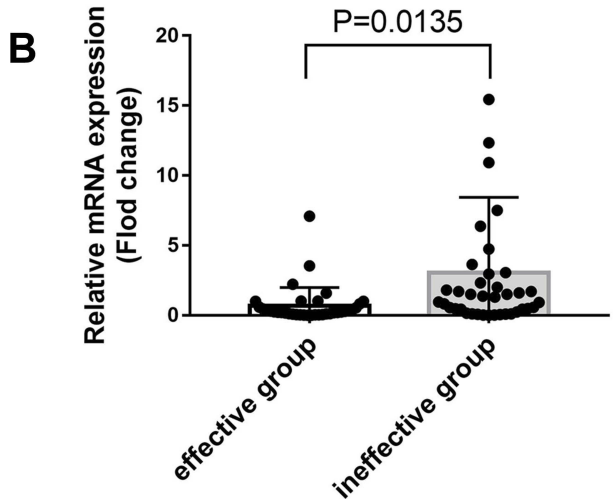

Figure 3 Immunohistochemistry and reverse transcription polymerase chain reaction (RT-PCR) were used to semi-quantitatively evaluate the expression level of Wnt5a. (A) Immunohistochemistry was used to semi-quantitatively evaluate the expression level of Wnt5a; (B) The expression level of Wnt5a in both effective group and the ineffective group was investigated by RT-PCR.

\section{Data Sharing Statement}

The datasets generated and analyzed during the current study are not publicly available due to patient consent is limited to this study.

\section{Acknowledgments}

The authors greatly appreciate all patients who contributed to this study.

\section{Funding}

This study was financially supported by Nurture projects for basic research of Shanghai Chest Hospital (Grant No. 2018YNJCM05) and Science and Technology Commission of Shanghai Municipality, China (Grant No.18441904700).

\section{Disclosure}

The authors stated that they had no conflict of interests.

\section{References}

1. Bray F, Ferlay J, Soerjomataram I, et al. Global cancer statistics 2018: GLOBOCAN estimates of incidence and mortality worldwide for 36 cancers in 185 countries. CA Cancer J Clin. 2018;68(6):394-424. doi: $10.3322 /$ caac. 21492

2. Lynch TJ, Bell DW, Sordella R, et al. Activating mutations in the epidermal growth factor receptor underlying responsiveness of non-small-cell lung cancer to gefitinib. $N$ Engl J Med. 2004;350 (21):2129-2139. doi:10.1056/NEJMoa040938

3. Rosell R, Carcereny E, Gervais R, et al. Erlotinib versus standard chemotherapy as first-line treatment for European patients with advanced EGFR mutation-positive non-small-cell lung cancer (EURTAC): a multicentre, open-label, randomised phase 3 trial. Lancet Oncol. 2012;13(3):239-246. doi:10.1016/S1470-2045(11)70393-X

4. Mitsudomi T, Morita S, Yatabe Y, et al. Gefitinib versus cisplatin plus docetaxel in patients with non-small-cell lung cancer harbouring mutations of the epidermal growth factor receptor (WJTOG3405): an open label, randomised phase 3 trial. Lancet Oncol. 2010;11(2):121-128. doi:10.1016/S1470-2045(09)70364-X
5. Engelman JA, Janne PA. Mechanisms of acquired resistance to epidermal growth factor receptor tyrosine kinase inhibitors in non-small cell lung cancer. Clin Cancer Res. 2008;14(10):2895-2899. doi:10.11 58/1078-0432.CCR-07-2248

6. Tan CS, Gilligan D, Pacey S. Treatment approaches for EGFR-inhibitor-resistant patients with non-small-cell lung cancer. Lancet Oncol. 2015;16(9):e447-e59. doi:10.1016/S1470-2045(15) 00246-6

7. Cho BC, Chewaskulyong B, Lee $\mathrm{KH}$, et al. Osimertinib versus standard of care EGFR TKI as first-line treatment in patients with EGFRm advanced NSCLC: FLAURA Asian subset. J Thorac Oncol. 2019;14(1):99-106. doi:10.1016/j.jtho.2018.09.004

8. Lin Y, Wang X, Jin H. EGFR-TKI resistance in NSCLC patients: mechanisms and strategies. Am J Cancer Res. 2014;4(5):41 $1-435$.

9. Ji P, Zhou Y, Yang Y, et al. Myeloid cell-derived LL-37 promotes lung cancer growth by activating Wnt/beta-catenin signaling. Theranostics. 2019;9(8):2209-2223. doi:10.7150/thno.30726

10. Li C, Xiao J, Hormi K, et al. Wnt5a participates in distal lung morphogenesis. Dev Biol. 2002;248(1):68-81. doi:10.1006/dbio. 2002.0729

11. Yang J, Zhang $\mathrm{K}, \mathrm{Wu} \mathrm{J}$, et al. wnt5a increases properties of lung cancer stem cells and resistance to cisplatin through activation of Wnt5a/PKC signaling pathway. Stem Cells Int. 2016;2016:1690896. doi:10.1155/2016/1690896

12. Huang CL, Liu D, Nakano J, et al. Wnt5a expression is associated with the tumor proliferation and the stromal vascular endothelial growth factor-an expression in non-small-cell lung cancer. $J$ Clin Oncol. 2005;23(34):8765-8773. doi:10.1200/JCO.2005.02.2871

13. Shibue T, Weinberg RA. EMT, CSCs, and drug resistance: the mechanistic link and clinical implications. Nat Rev Clin Oncol. 2017;14(10):611-629. doi:10.1038/nrclinonc.2017.44

14. Dai FQ, Li CR, Fan XQ, et al. miR-150-5p inhibits non-small-cell lung cancer metastasis and recurrence by targeting HMGA2 and beta-catenin signaling. Mol Ther Nucleic Acids. 2019;16:675-685. doi:10.1016/j.omtn.2019.04.017

15. Wang J, Chen J, Jiang Y, et al. Wnt/beta-catenin modulates chronic tobacco smoke exposure-induced acquisition of pulmonary cancer stem cell properties and diallyl trisulfide intervention. Toxicol Lett. 2018;291:70-76. doi:10.1016/j.toxlet.2018.04.003

16. Konduri K, Gallant JN, Chae YK, et al. EGFR fusions as novel therapeutic targets in lung cancer. Cancer Discov. 2016;6 (6):601-611. doi:10.1158/2159-8290.CD-16-0075

17. Ettinger DS, Wood DE, Akerley W, et al. Non-small cell lung cancer, version 6.2015. J Natl Compr Canc Netw. 2015;13(5):515-524. doi:10.6004/jncen.2015.0071 
18. Huang L, Fu L. Mechanisms of resistance to EGFR tyrosine kinase inhibitors. Acta Pharm Sin B. 2015;5(5):390-401. doi:10.1016/j. apsb.2015.07.001

19. Kobayashi S, Boggon TJ, Dayaram T, et al. EGFR mutation and resistance of non-small-cell lung cancer to gefitinib. $N$ Engl J Med. 2005;352(8):786-792. doi:10.1056/NEJMoa044238

20. Sequist LV, Waltman BA, Dias-Santagata D, et al. Genotypic and histological evolution of lung cancers acquiring resistance to EGFR inhibitors. Sci Transl Med. 2011;3:75ra26.

21. Engelman JA, Zejnullahu K, Mitsudomi T, et al. MET amplification leads to gefitinib resistance in lung cancer by activating ERBB3 signaling. Science. 2007;316(5827):1039-1043. doi:10.1126/science.1141478

22. Rho JK, Choi YJ, Kim SY, et al. MET and AXL inhibitor NPS-1034 exerts efficacy against lung cancer cells resistant to EGFR kinase inhibitors because of MET or AXL activation. Cancer Res. 2014;74 (1):253-262. doi:10.1158/0008-5472.CAN-13-1103

23. Ghosh G, Lian X, Kron SJ, et al. Properties of resistant cells generated from lung cancer cell lines treated with EGFR inhibitors. BMC Cancer. 2012;12(1):95. doi:10.1186/1471-2407-12-95

24. Anastas JN, Moon RT. WNT signalling pathways as therapeutic targets in cancer. Nat Rev Cancer. 2013;13(1):11-12. doi:10.1038/nrc3419

25. Le PN, McDermott JD, Jimeno A. Targeting the Wnt pathway in human cancers: therapeutic targeting with a focus on OMP-54F28. Pharmacol Ther. 2015;146:1-11. doi:10.1016/j.pharmthera.2014.08.005

26. Kang MI, Baker AR, Dextras CR, et al. Targeting of noncanonical Wnt5a Signaling by AP-1 blocker dominant-negative jun when it inhibits skin carcinogenesis. Genes Cancer. 2012;3(1):37-50. doi:10. $1177 / 1947601912448820$
27. Bo H, Zhang S, Gao L, et al. Upregulation of Wnt5a promotes epithelial-to-mesenchymal transition and metastasis of pancreatic cancer cells. BMC Cancer. 2013;13(1):496. doi:10.1186/1471-240713-496

28. Lee GT, Kang DI, Ha YS, et al. Prostate cancer bone metastases acquire resistance to androgen deprivation via WNT5A-mediated BMP-6 induction. Br $J$ Cancer. 2014;110(6):1634-1644. doi:10.10 38/bjc. 2014.23

29. Kanzawa M, Semba S, Hara S, Itoh T, Yokozaki H. WNT5A is a key regulator of the epithelial-mesenchymal transition and cancer stem cell properties in human gastric carcinoma cells. Pathobiology. 2013;80(5):235-244. doi:10.1159/000346843

30. Cao J, Wang Q, Wu G, et al. miR-129-5p inhibits gemcitabine resistance and promotes cell apoptosis of bladder cancer cells by targeting Wnt5a. Int Urol Nephrol. 2018;50(10):1811-1819. doi:10. 1007/s11255-018-1959-X

31. Zhang X, Lou Y, Zheng X, et al. Wnt blockers inhibit the proliferation of lung cancer stem cells. Drug Des Devel Ther. 2015; 9:2399-2407. doi:10.2147/DDDT.S76602

32. Dean M, Fojo T, Bates S. Tumour stem cells and drug resistance. Nat Rev Cancer. 2005;5(4):275-284. doi:10.1038/nrc1590

33. Zhang X, Hu F, Li C, et al. OCT4\&SOX2-specific cytotoxic $\mathrm{T}$ lymphocytes plus programmed cell death protein 1 inhibitor presented with synergistic effect on killing lung cancer stem-like cells in vitro and treating drug-resistant lung cancer mice in vivo. $J$ Cell Physiol. 2019;234(5):6758-6768. doi:10.1002/jcp.27423
OncoTargets and Therapy

\section{Publish your work in this journal}

OncoTargets and Therapy is an international, peer-reviewed, open access journal focusing on the pathological basis of all cancers, potential targets for therapy and treatment protocols employed to improve the management of cancer patients. The journal also focuses on the impact of management programs and new therapeutic

\section{Dovepress}

agents and protocols on patient perspectives such as quality of life, adherence and satisfaction. The manuscript management system is completely online and includes a very quick and fair peer-review system, which is all easy to use. Visit http://www.dovepress.com/ testimonials.php to read real quotes from published authors. 